\title{
BURROWING OWLS IN SOUTH-CENTRAL SASKATCHEWAN
}

By JIM A. WEDGWOOD, 610 Leslie Ave., Saskatoon, Sask.

In a rash moment I agreed to a competition with Bernie Gollop, Editor of the Blue Jay, to see who could find the most Burrowing Owls within 100 miles of Saskatoon in 1975. For the Wedgwoods the contest started in earnest on July 1.

We had no great expectations. The annual Mayday Bird Count, when teams of observers scour the Saskatoon district, had yielded a mere six observations of the conspicuous bird in the last 10 years. K. O. Butts noted that the Burrowing Owl has been on and off the endangered species list.

Frank Roy wrote in "Birds of the Elbow" about the Burrowing Owl: "Fairly common summer resident, often returning year after year to the same nest-hole. . Partial to pastureland." Pough noted in the "Audubon Guides": "This is a bird of the open, treeless, short-grass country..." Godfrey in his excellent book, "The Birds of Canada", shows the breeding range in Saskatchewan extending only as far north as Prince Albert. The records of the Saskatoon Bird Survey of 1966-70, when observers reported birds in a 60-mile square block surrounding the city, contained a few notes on the scarce bird.

From these leads a plan evolved: visit previously reported sites to look for owls and to acquire a better understanding of their habitat, then search the south part of the Saskatoon Area and a Sector south of that between Highway 11 on the east and Highway 4 and 7 on the west.

At 8:43 p.m. on Saturday, August 12, Gollop conceded, thoroughly beaten. Victory was ours, an 'owling success.

We continued the search but changed the emphasis. While still seeking finds, repeat visits were made to known sites to obtain additional information about the bird. Our and the Gollops' (Maddie included) trips were coordinated. The overall result was a semi-formal survey yielding some data on the Burrowing Owl in part of southcentral Saskatchewan.

The account is based on our notes, on Bernie Gollop's records for 1975 and previous years and on the Saskatoon Bird Survey data. Observations in 1975 by E. A. Driver, Lynn Oliphant and by three farmers have been incorporated and historical information obtained from farmers and others has been used. The Editor kindly drew numerous references to my attention.

The Region. The map shows the Saskatoon Bird Survey Area and the Sector to the south of it, the two areas together forming the Region searched for Burrowing Owls in 1975. The Region occupies 9,149 square miles: 3,600 in the Saskatoon Area, 5,549 in the Sector. It is 124 miles north-south and averages 74 miles wide. It is mostly loam plains under crop cultivation.
The Region is partly in the extreme north of the Great Plains and partly in the southern parkland with typical aspen bluffs in the north and east. The Boreal forest lies 30 miles to the north. The only trees growing naturally in south half are in coulees and valleys with some in hills. A transition zone (Mid-grass Prairie), between the Short-grass or Mixed Prairie of southwestern Saskatchewan and ranker 


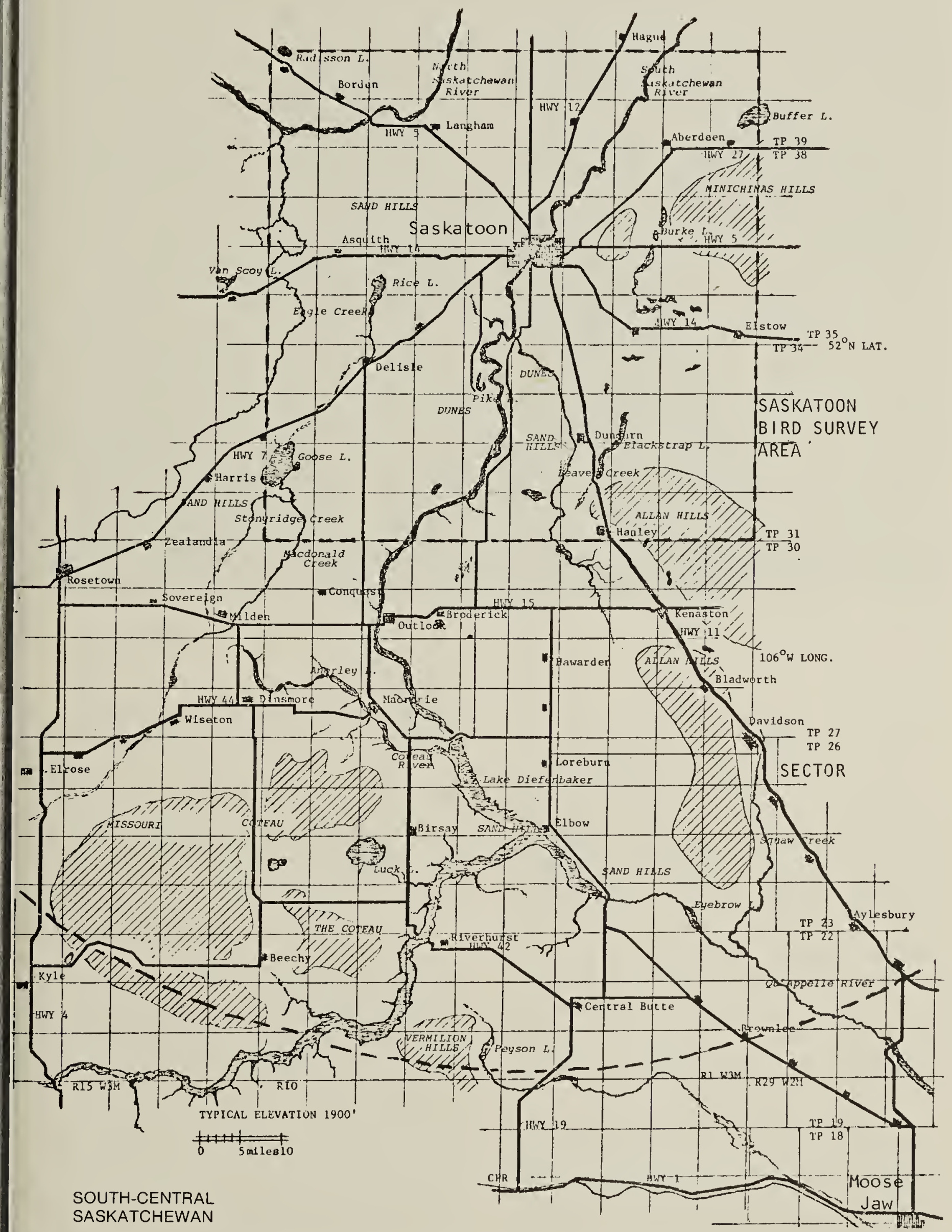

Readers wishing further details should consult the Atlas of Saskatchewan by J. H. Richards and R. I. Fung, 1969. Univ. Sask. 236 p. 
grasses of Parkland Prairie, angles across the Region from northwest to sou theast.

The Search. In the Saskatoon Survey Area previously reported sites and likely tracts were checked by the Gollops and Wedgwoods with some duplication.

In the Sector, time was spent at first in the south part assuming owls would be more numerous there. Results were disappointing. A belt angling across the north half proved more productive and later efforts were largely devoted to it. The few sites known from previous years were checked. All occupied sites in the northern portion were revisited at least twice and most four times. There was no opportunity for a second trip to the 11 active burrows found in the south portion.

Soils and physiographic maps and aerial photos were used extensively along with the old standbys, topographical maps. Likely tracts were spotted from the aerial photos - not always successfully at first because learning to interpret them reliably took much of the season. The maps, especially the soils maps, were extremely useful in locating possible habitat.

Hills include the Allan, Vermilion, Eyebrow and "Strawberry" (Minichinas) Hills, and the extensive Missouri Coteau. They are largely under cultivation, but still contain considerable native prairie.

Annual Cycle. From all sources we had a total of 247 owl observations spanning from 1952 to 1975 . These data provide a picture of the bird's arrival and departure and general activities while in the Region.

Inbound migration peaks around April 21. The earliest arrival was April 12 and the latest confirmed occupancy was May 8. Most of the initial observations were of pairs, indicating that most owls either arrive paired or pair with little delay. Pairs were seen more often than lone birds until midMay, after which singles outnumbered pairs until the end of June. General onset of incubation in mid-May would account for the switch in proportions of singles and pairs observed, the females being underground on the nests.

A. W. Eckert wrote that the Burrowing Owl, like other owls, lays an egg every second day, approximately, and about 29 days are needed for incubation. Lise Thomsen in her California study concluded that incubation commences when the first egg is laid and that 10 to 14 days elapse between hatching and appearance of the owlet above ground. There is thus about 41 days from onset of incubation to first appearance of the young. This reconciles with incubation commencing in mid-May and young appearing in late June in our Region.

June 23 was the earliest an owlet has been observed and June 29 the earliest date for a complete family, seven nestlings. In the former case the egg was probably laid about May 11 and in the second clutch the first egg could have been laid as early as May 3. From personal experience the soil can still be frozen at the level of the nest on this date in most years. At the other extreme, the youngest bird in a family of eight juveniles seen on August 9 in 1975 still had down feathers sticking out here and there, a condition usually not observed after early July, The first egg in that clutch would have been laid about June 17, which implies that renesting may occur when the initial attempt fails.

The reports showed an increase in the incidence of pairs and singles around August 21. About this time in 1975 we started to encounter vacated sites. On the first weekend of September, of 11 sites occupied during the summer, eight still had families, one had a lone bird and two were vacant. On September 21 at 11 other sites there were two still with families (renesters?), four with pairs, two with loners and two were vacant. The interpretation: fledging is largely complete by mid-August; while some immatures leave, most stay on site, dispersing to burrows of their own; a few families relocate - we found three confirmed cases; and by mid-September most of 


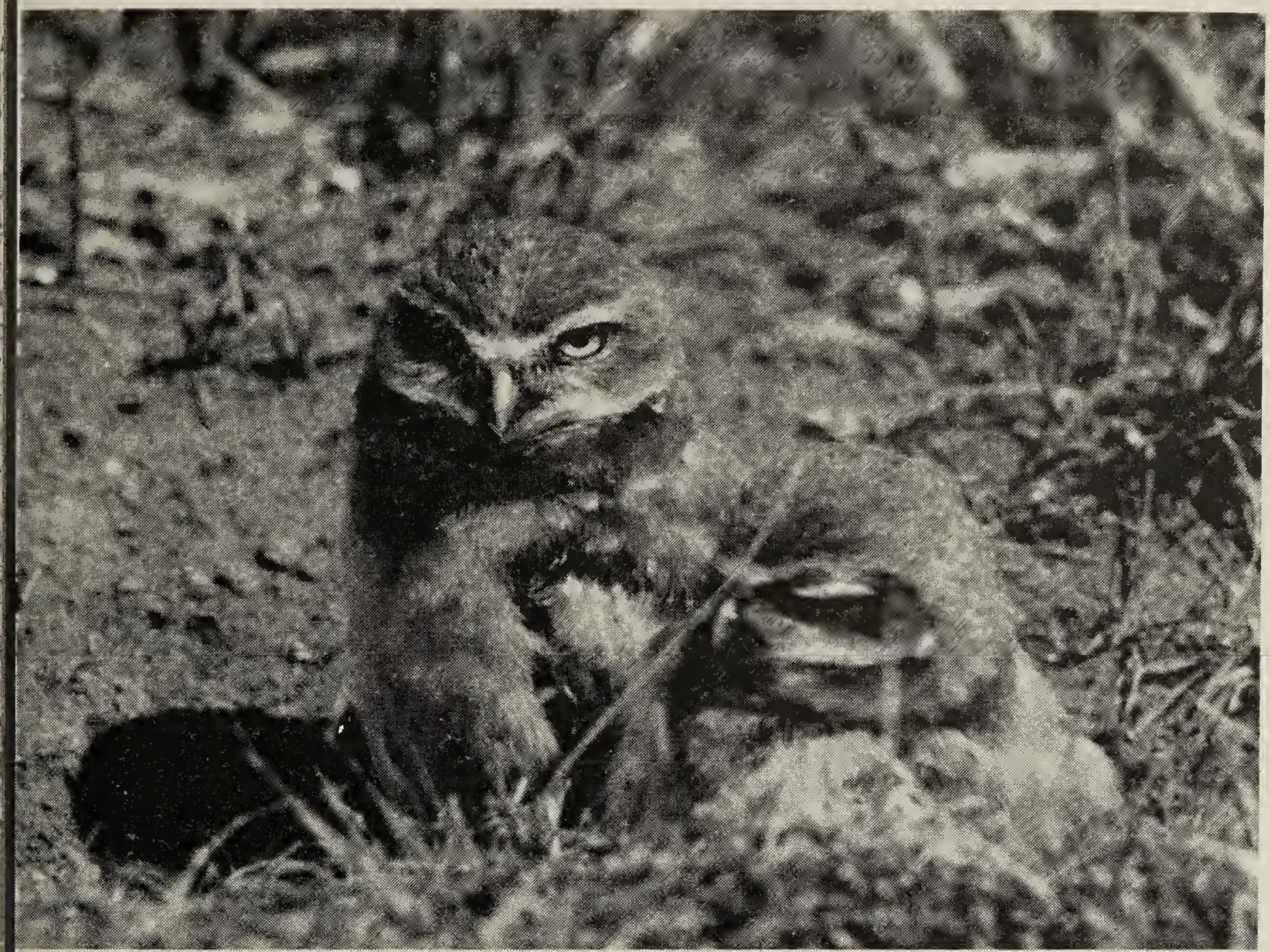

Young Burrowing Owls

R. E. Gehlert

the young have gone, some adults (females?) have vacated, and the occasional male has also left.

Few birds remain into late fall. On October 5, 1975, only three out of 15 sites still had owls and one new single occupancy was found. October 8 is the latest an owl has ever been reported in the Saskatoon Area.

For most of July identifying young, females and males was not difficult, except at long range. The young bird's rusty throat band is distinctive and, as a rule, the male is decidedly lighter colored than the female. (Bleaching by the sun and feather wear from hunting are the reasons offered for the difference. Being below ground for much of six weeks, the female is not exposed to these influences. According to R. A. Grant the distinction is not completely reliable because of individual variations).

Identifying family members became more difficult in late July. The young were molting into an adult-like plumage and tonal differences in the adult plumages were less pronounced. Counts in this period were usually only of total families. However, the male's behaviour often served to identify him as he continued to react to disturbances by giving the comical bobbing distraction display and alarm call. This reaction was observed in September even when only two birds, presumably the adults, remained on the site.

By mid-September both adults appeared much darker. According to Eckert the annual molt occurs in August-September. Occasionally where the family was still bunched, rather than scattered over the site, thus affording a comparison, the young could again be identified by their lighter plumage.

Very much in evidence until early September, the male was often spotted before the family was found. Though 
occasionally on a post or rock, he was usually on a sentinel mound up to a hundred yards from the nest burrow; one was seen a third of a mile away. If disturbed he would sometimes fly over the nest burrow on his way to another sentinel perch. In July the female was usually with the young at the nest mound. If alarmed, she went down the nest tunnel with the young or flew to another mound.

At first the young clustered timidly at the nest mound, disappearing at the least alarm. Repeat visits to some sites indicated that birds had been missed on the earlier trips. By August the juveniles were ranging away from the home burrow in ones and twos and using mounds, burrows and "foxholes" of their own, again making accurate counting difficult.

About mid-September the owls grew quite secretive, often only the top of the head and the bright yellow eyes being visible. The birds did less daytime flying and hunting than in August when all members of the family were more or less active during the day. The adult behavioural changes seemed to coincide with the fall molt.

\section{Seasonal Movement, Migration and Win-}

ter Range. In 1975 four sites were vacated before the general exodus of young started in mid-August. A pair seen on May 11 had disappeared by July 13 - possibly they moved to another site. A family of two adults and two young first seen on July 6 was down to three members on July 13 and had vanished by July 16. Two lone birds presumed to be nonbreeders were gone by August 2 and 9 meagre data but suggestive that nonbreeders might not remain on the sites for the full season.

By September 1, approximately 106 immatures and adults were unaccounted for from 24 sites checked before that date. A few could have been missed on second counting and mortality could have taken some. The majority, however, were presumably birds which had vacated the sites. Yet only six new sites containing 23 birds were found after August 31, and some of these would not really be new occupancies as owls could have been there all summer. There were obviously too few new occupancies to account for the numbers vacating other sites, or for dispersals from neighboring regions. If there had been any significant amount of premigratory wandering, the incidence of new sightings late in the season should have been greater.

Unless birds flocked into the south part of the Sector, which was not revisited, the indication was that there was little wandering within the Region. This suggests that most of the birds migrate a considerable distance upon leaving the home site. Also implied is that some of the immatures migrate on their own since one or two birds were still on 17 of 20 sites checked on the second and third weekends in September and some of them were adults.

Nothing is known about the migration route or the winter range for Burrowing Owls from this Region.

There have been no recoveries of birds banded in Saskatchewan, including young at six burrows in the Saskatoon Area and at one in the Sector.

Because of the species' strong attachment here to mounds, tunnels and "foxholes" during the postbreeding as well as in the breeding season, Ligon's and Coulombe's references to migrants and nonmigrants using burrows during winter in the American Southwest are significant. For both migratory and nonmigratory populations the burrow attachment seems to be an element of the entire life cycle.

It could be that the welfare of the central Saskatchewan population is dependent on, among other things, an adequate stock of burrows on the winter range as well as in this Region. Whether the condition holds while the bird is migrating is an interesting question.

Use of Sites and Trends. J. F. Roy and others have noted that the owl makes repetitive use of a plot, even returning to the same burrow year after year. In 


\section{It \\ 120.2.

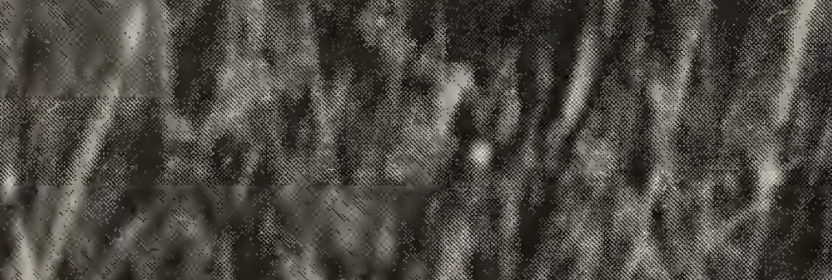 s.om}

(6) 2xy n.

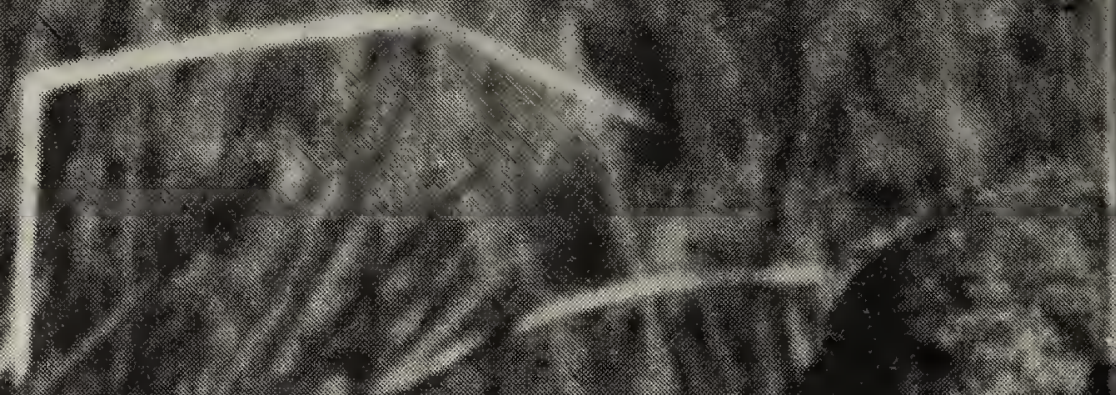

\section{(zer -10}

trs.

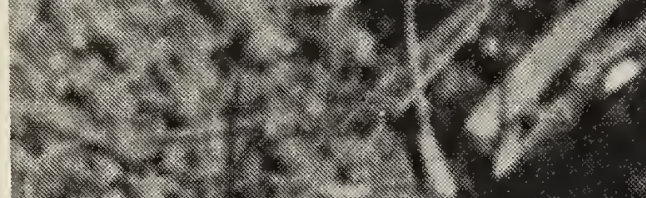

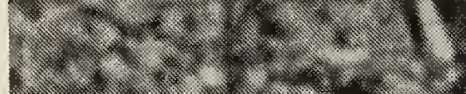

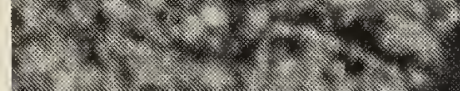
8h-
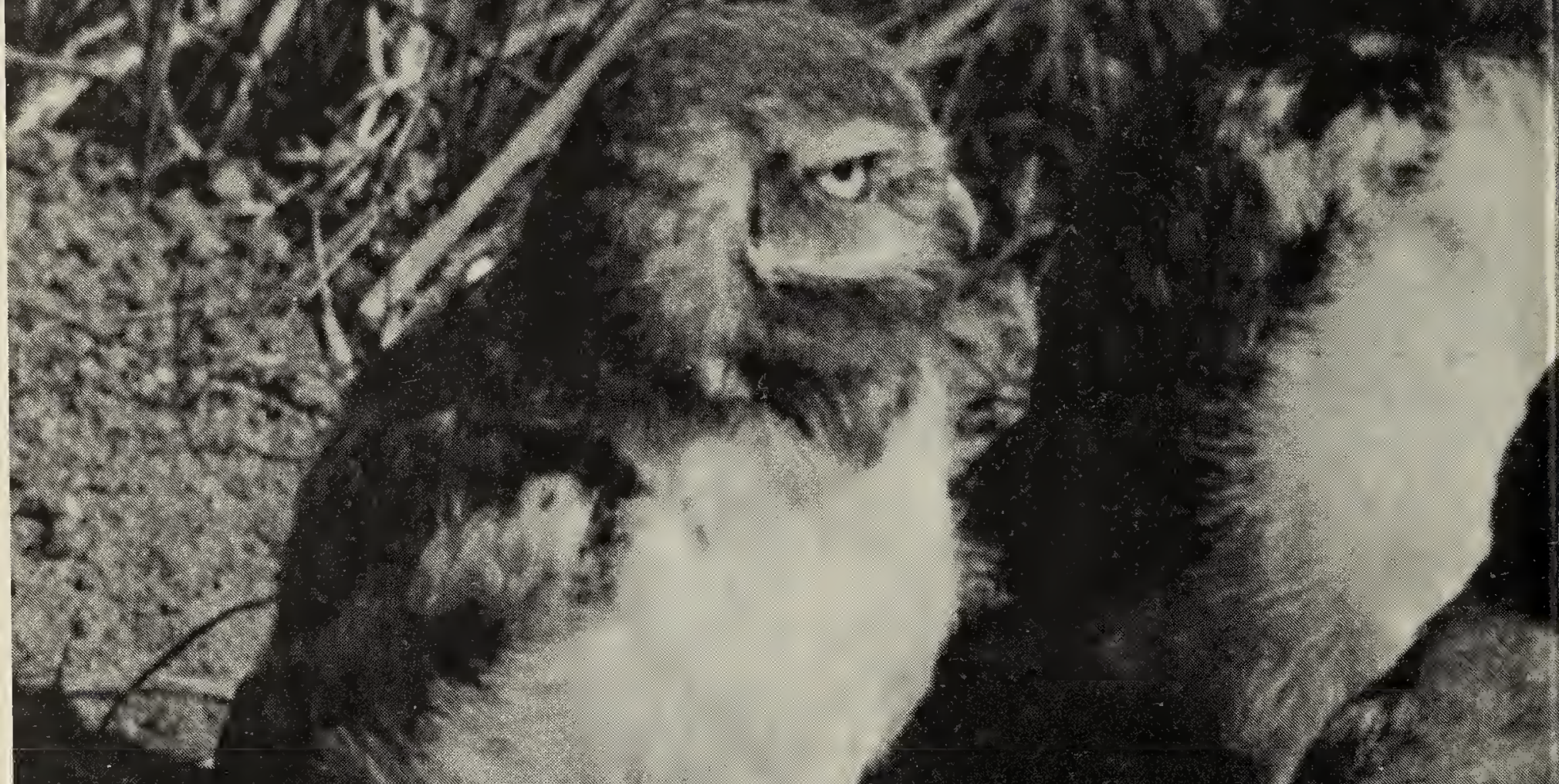

(2)
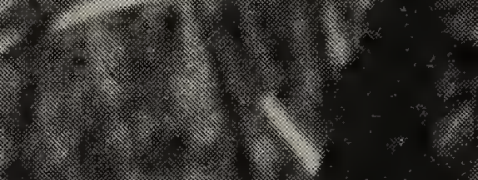

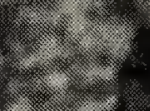

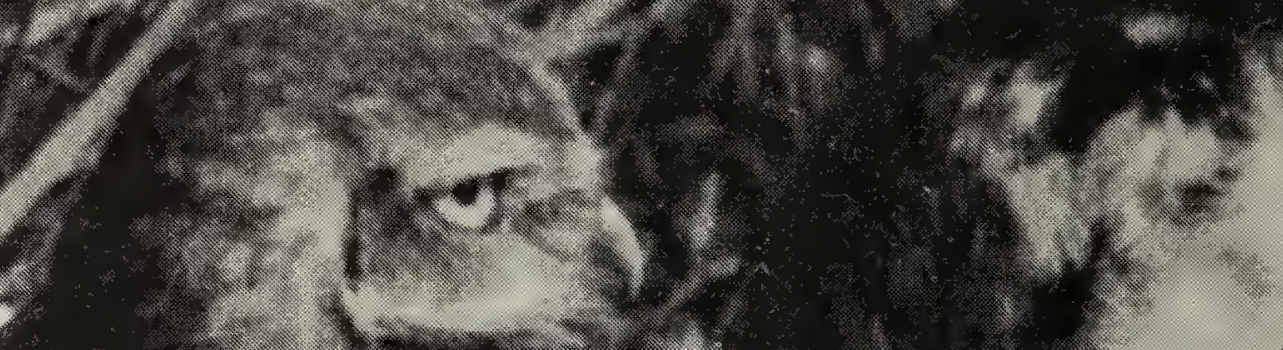

2.

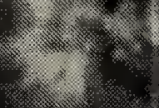


Though less is known about the history of sites in the Sector, we found examples of both repetitive occupancy and a decline in numbers there too. We have driven by a pasture near Broderick four times over the last six summers, and seen an owl family on each occasion, one burrow mound being used in the first and last years, another in the intervening years. One Conquest district farmer said that a pair has nested in various spots in his pasture for each of the six years since he moved onto his farm. A Central Butte farmer told us that there had been owls in his pasture every year for 40 years "but there used to be more broods". Of 11 previously reported sites in the Sector, only three were occupied in 1975. One of these earlier sites was of unusual interest. W. E. Clyde Todd, while in the Davidson district in 1932, "saw a pair of Burrowing Owls 14 miles $W$ of Davidson" - and 14 miles W of Davidson we found a family 43 years later.

The only colony we found contained six or eight active burrows with a population conservatively estimated at 42 birds on July 20 . Accurate counting was difficult. The males seemed hyperactive, flying around randomly and occasionally crossing sites to parts of the field not occupied by the colony. Territorial boundaries seemed nonexistent. The young were surprisingly advanced and some were on the wing. Because of the terrain it was not possible to see all birds on all sites from a single observation point outside the colony. On August 17 the count was down to around 15 owls, at least two families having moved into adjoining pastures.

The colony occupied some 80 acres in a pasture of about 250 acres. The undulating field, underlain with gravel, was lightly strewn with rocks and scattered patches of buckbrush. Much of it was a rougher, more cluttered habitat than the typical one.

In only three other instances was more than one family found in a field. In one there were two families about 200 yards apart; in another the two home burrows were 300 to 400 yards from each other. The comments of several farmers suggest that colonial nesting was formerly a more common occurrence.

1975 Owl Population. A total of 276 Burrowing Owls was found in the region in 1975. Thirty-seven were in the Saskatoon Area at 11 sites and 239 in the sector at 40 sites. Included are three loners, three birds presumed to be post-breeding wanderers and four pairs which were either nonbreeders or breeding failures. There were 45 successful breeding pairs with at least 172 young.

The largest family seen in 1975 had 11 young. As the number of eggs in the clutch is given by Eckert as six to 12 , by Bailey as six to 11 and by Ligon as eight to 12 , this one was a near record - another 'owling success. At the other extreme three families had but a single owlet each.

In estimating reproduction, only counts made between July 15 and August 15 were used, after the young were above ground but before the main dispersal started: 134 birds in 21 families - theoretically 4.4 young per family. Incorporating my assumptions for necessary corrections indicates that roughly 4.6 juveniles per breeding pair fledged to independence in the Region in 1975 . $^{*}$

\footnotetext{
*The need for these corrections in a computation of fledging is brought about because our objective was to find the most birds, not to conduct a rigorous study of reproduction. In the estimate of 46 juveniles I have attempted to allow for,

-birds missed on counts - though three of the second visits did result in higher counts, it was not possible to revisit all the sites.

-one-adult families - one family was known to be shy an adult. As noted elsewhere, it became difficult to distinguish young from adults in August, and to assume two adults per family for counts in this period would not necessarily be correct.

-reduced counts in hot weather - five of the counts included in the computation were made at mid-day during a heat wave. H. N. Coulombe observed that many Burrowing Owls stay underground on a hot day.

-mortality in the period prior to fledging. The counts used in the computation were spread over the four weeks prior to August 15 when fledging was adduced to be essentially finished. Some mortality among the young, particularly for those counted in the last half of July is to be assumed.
} 
Counts of 15 families (94 birds) in July, again with assumed corrections, yield a conservative estimate of about 5.1 young produced (reaching the surface) per breeding pair. This suggests that roughly $90 \%$ of the young reaching the surface finally fledged.
A comparison with reproduction studies undertaken elsewhere could indicate whether family success in this region is to be considered good or poor. However, surprisingly few detailed studies have been made on the Burrowing Owl.

Table 1 includes those known.

\section{Table 1. Burrowing OwI Reproduction Data}

Western
Minnesota

$1963-64$

5

54

Western

Oklahoma

1970

1965

1966

$89 \%$

$61 \%$

$56 \%$

$91 \%$
Number of breeding pairs in reproduction determination

Breeding adults per cent of adult population

Young reaching surface per breeding pair

Independent young per breeding pair

Per cent of original young fledged

Study area Regional

Mid-August Wedgwood

$86 \%$

$5.1 \pm$

$4.6 \pm$

$90 \pm \%$
Period for reproduction determination

Observer
Regional

Prairie dog Two colonies plus surrounding region

\section{First of} August $59 \%$

Incidence of family sizes in south-central Saskatchewan, 1975 (exclusive of colony)

Total number of adults and young in family Number of families

A precise comparison of the results of these studies should not be attempted. Not only were there differences in the methods of conducting the studies, but there were also differences in the interpretations of the terms. The definitions applied to "adult population", "breeding pair" and "fledging" were not necessarily the same from one study to another. Also, see text for adjustments made to Wedgwood data.

'Given as productivity of 2.2 and 1.7 young per breeding adult in the original report. 
One might conclude that reproduction in our region is not unsatisfactory. However, the comparison is weak. It is not known if any study period was an average owl year, and the California results show that much variation is possible. The reproduction level needed to balance losses is not known. Two studies were highly site specific, that in California being of a colony on an airport, that in New Mexico being of two colonies, one along a railway embankment, the other in an outwash. On the other hand the Minnesota and Saskatchewan studies were regional.

Food. Often owls were seen chasing insects on the ground or in the air. Enough were identified as grasshoppers to suggest that this insect is a primary food item.

The pellets regurgitated by owls and hawks consist of the indigestible parts of the materials consumed and provide clues to part of the diet. Our own examination was confined to visual inspection from mid-August onward. (We usually refrained from intentionally walking up to any nest on or in the ground containing eggs or young so as not to leave tracks or scent a predator could follow to the nest.) Most of the pellets appeared to consist largely of grasshopper casings, and the consumption of grasshoppers by Burrowing Owls would seem to be prodigious in August.

Two pellets collected by J. B. Gollop in September were examined microscopically by M. E. Taylor. He identified carrion beetles (Silphidae), ground beetles (Carabidae) and at least three grasshopper species (Acrididae). In addition to the indigestible parts of these adult insects, there were approximately 68 mandibles, most of larvae. A considerable amount of vegetative matter was also present.

Only a few pellets contained fur or bone. It was common, however, to see small bones scattered on the mound and in the burrow entry. One pellet was made up mainly of a rabbit's foot complete with claws and presumably taken as carrion. The largest complete bone we saw at an entry was identified by R. L. Rausch as the legbone of a 13 lined Ground Squirrel. He also identified skull parts of Meadow voles in another pellet. A male was seen with a mouse in its talons flying to a nest mound, where it landed, released the mouse and took off without pausing. A young owl promptly picked up the mouse. Only once were feathers definitely not from a Burrowing Owl seen in a tunnel entry. They appeared to be from a crow, again assumed to be carrion.

Hazards. One of several observations of the Burrowing Owl's reaction to aerial predators may be of interest. When first coming upon the colony, only seven scattered adults were seen and no young were in evidence. Three Swainson's Hawks were alternately circling low overhead and perching on posts beside the field. The next day about 42 owls were in view, many of them active. No hawks were seen.

Of 477 owls banded in the Dakotas from 1931 to 1934 by Brenckle and Berner, 10 were from birds killed by traffic - and one would have to assume that undiscovered and unreported instances would have increased the proportion. Presumably referring to the United States, Eckert wrote that Burrowing Owls suffer considerable losses from road kills. What is the situation here? That the largest family, one nesting within 50 yards of a busy highway, should be reduced from 13 to four birds in six weeks prompted the question.

The owls frequent roadways. One bird was found dead on a road 200 yards from an occupied pasture and there is a known road kill. There are three reports of Burrowing Owls being spotted in car headlights in the Area. A farmer remarked, "I have often seen ground owls playing on the road at night." I take "playing" to mean chasing insects; we saw a family catching grasshoppers on a road in midmorning. One-third of the families located in 1975 were on sites adjoining the road allowances of highways or busy grid roads, and of these threequarters had nest burrows within 50 yards of the roadways. If the owl is 


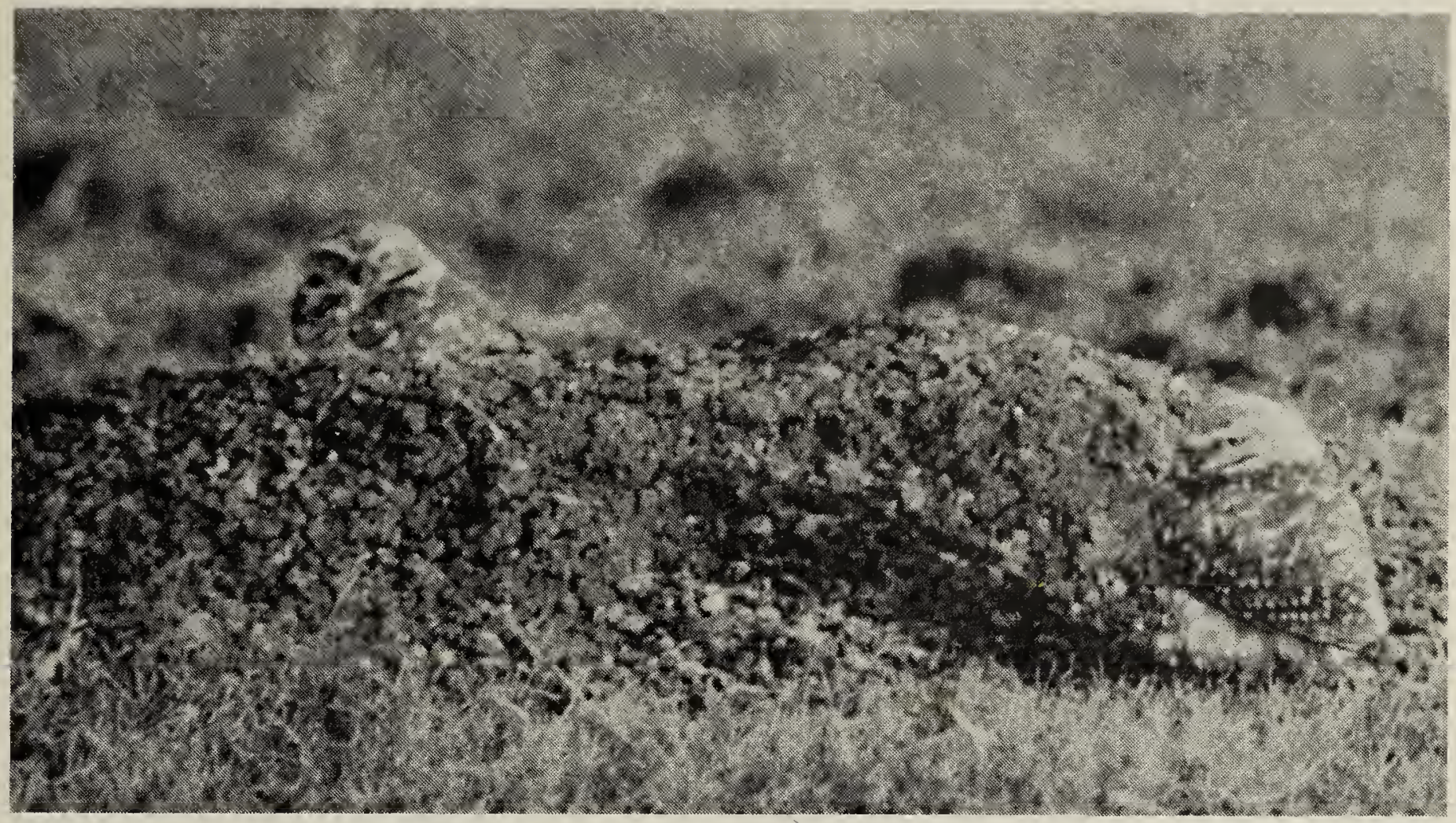

Burrowing Owls at mound.

Fred Lahrman

prone to road kill, there may be cause for concern in view of the numbers living close to traffic. Unfortunately insufficient data exist for a comparison of losses in families close to and remote from traffic. All we have is an indirect indication: five families near traffic decreased 40 per cent in size in an average of 35 days.

The use of agricultural chemicals in connection with private pastures varies considerably from farm to farm. district to district and year to year. Grasshopper poisons may be applied to pastures, adjoining areas and roadsides in years of infestation. An intensive study would be needed before any firm conclusion could be reached about the effects on local owls, especially from the poisoning of grasshoppers which appear to be a food staple.

Herbicides are sometimes used to eradicate buckrush. Buckrush control would seem to improve Burrowing Owl habitat.

Nothing was learned from our survey about attrition due to rodent and predator control programs or from indiscriminate shooting, all identified by Grinnell and Miller as causes of owl losses in California.
The Burrow. Fourteen burrow mounds were examined closely. The general characteristics of many others could be determined from a distance. Badgers appear to be the main providers of owl burrows in the Region. Hole size and other signs were usually typically badger: the entries were in, not beside, the mound and the mounds were extensive, the soil having been churned up by the original occupant over an area 30 feet across in some cases. Invariably there was more than one hole or remains of a hole. The owls used partly filled in holes as "foxholes", sheltering in them as well as in tunnel entries.

Two and possibly three nest burrows were too small to have been dug by a badger or fox. The tunnels were oval in cross section, higher than wide. They were assumed to be enlarged ground squirrel holes.

Only one hole was thought to have been excavated by the bird itself. The oval tunnel was wider than high. It was in very coarse dense sand, the only one found in sand.

S. J. Shadick found a rather unusual burrow and we came across an identical one four miles away. The hole, about a foot in diameter. went almost straight down some two and a half feet 
before going off horizontally. (Usually the first section of a tunnel ramps down at about a 30-degree angle). How any animal could have dug the hole was difficult to conceive, as it would have been standing on its head kicking dirt straight up. One hole had served as a nest burrow, the other as a secondary burrow.

Habitat. Our notes on 82 of the 95 places where owls have been seen since 1952 yield a fairly complete picture of habitat.

Typical habitat is a pasture, with short, prairie cover, no trees and mainly devoid of brush, on terrain no more than gently sloping or rolling, and with a population of ground squirrels: a flattish, open, short-grass prairie pasture with ground squirrels. Only 11 sites were elsewhere in pastures and these are described under Exceptional Sites.

The conviction grew that the key criterion is an adequate stock of animal holes and mounds for the family. The presence of ground squirrels was usually an indication that such existed. More precisely, a ground squirrel population probably reflected that the site had been badger territory. Exceptions were found in other characteristics of typical habitat, but no owl was seen other than at or near a tunnel or "foxhole" or a look-out mound except for the occasional bird on a post. From observations of the owl's reaction to Swainson's Hawks, there is obviously survival value in the bird's almost constant association with hole and mound and in the family having access to a number of holes dispersed across the site.

The 71 occupied pastures were of three kinds: 23 farmyard pastures, 47 range pastures and one community pasture. The typical farmyard pasture is a small field adjacent to a still-used farmyard; it originated as a pasture for the farmer's milk cows and horses. Most are on prime agricultural soils. Occurrence is random.

A range pasture is usually a larger field up to a section in size. Most are on poorer soils - saline, gravelly, stony or sandy. Occurrence is generally related to the distribution of these soils. The main incidence is along the Macdonald Creek drainage course which runs for 50 miles from the Missouri Coteau to Goose Lake. A string of range pastures, some in native prairie, some in tame grass, follows the course, broken in only a few places with cultivated areas. Twelve owl sites were found along this stretch, mostly on grazed or stunted native cover and, with one exception, only where the terrain was a broad swale not more than a few feet below the surrounding plain. The Stonyridge Creek drainage course and three big saline depressions northeast of Broderick, west of Hanley and east of Central Butte also contain several range pastures. Altogether 25 owl sites, about half the active sites, were found in these five tracts in 1975.

Only three sites were in hill country, two in the Allan Hills and a 1967 occupancy in the "Strawberry" Hills. Each one, however, was not actually on a hill, but on less convoluted bottom land between hills. Five other sites were on rolling land. Only one site was found in the thousands of acres of short prairie blanketing the brows, sides and some bottoms of coulees and valleys in the Region. The remainder were in terrain no more than gently undulating or slightly sloped.

Exceptions to the short-grass criterion for typical habitat were few. Only six of the active sites in 1975 were in ungrazed areas, and of these, three were in railway right-of-way. However, all six burrows were in patches of stunted growth surrounded by medium or rank grasses. Rarely, other occupied fields contained patches of taller growth or buckbrush. It is ironic that naturalists take a dim view of overgrazing, yet such a stock management practice produces prime Burrowing Owl habitat here.

The thought that overgrazing might mean an inadequate food supply was dispelled upon finding owls on an alkali flat. In the vicinity of the nest burrow grasses were stunted and 


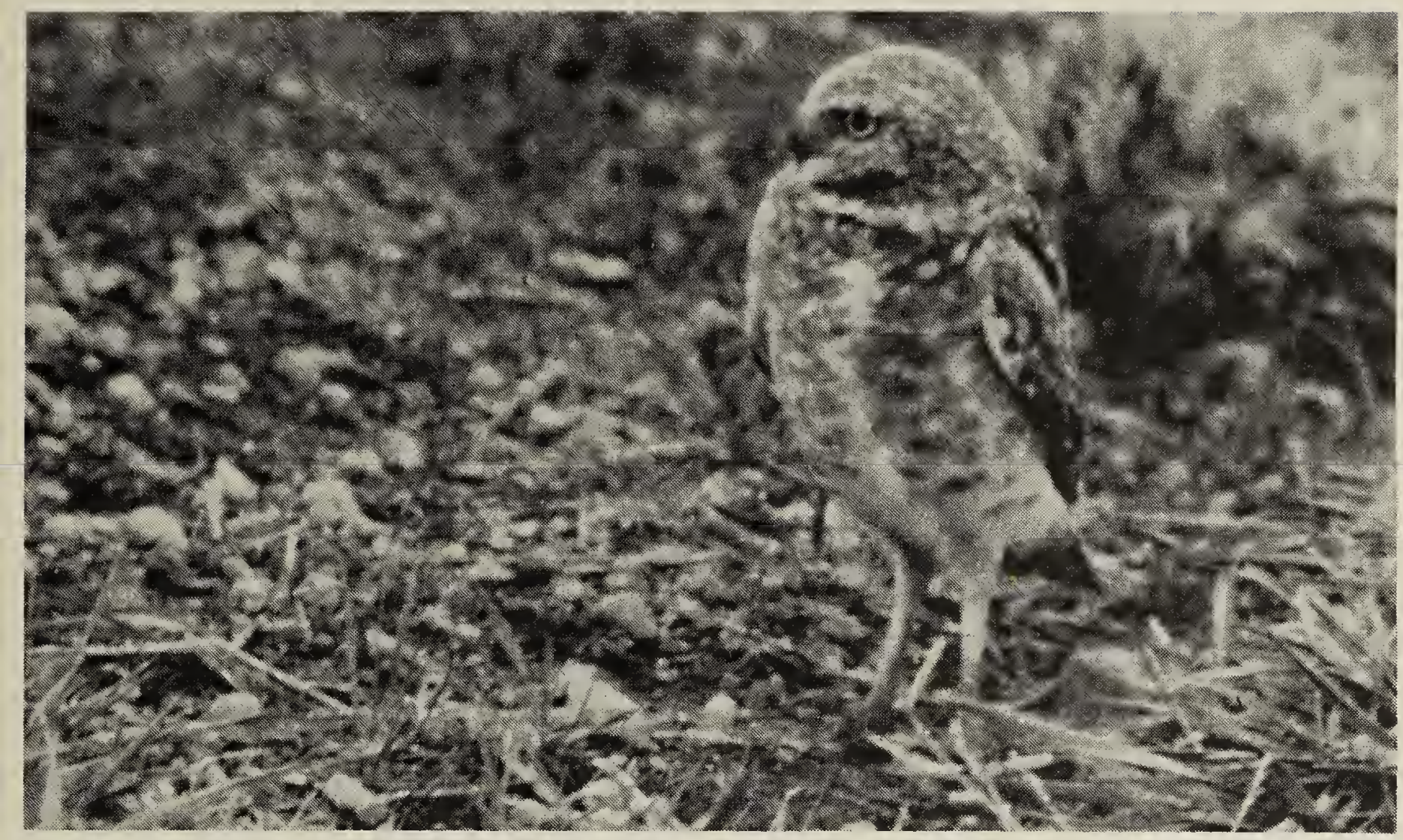

Adult Burrowing Owl

Fred Lahrman

sparse, with considerable bare ground showing, Prickly Pear Cactus dominated. This territory sustained one of the largest families - eight nestlings, seven of which fledged. One could well imagine this desert-like place was the species' original habitat. The owl's long legs, ability to run fast and its manoeuverability seemed suited for chasing prey through sparse vegetation. Strangely, the plumage colouration seemed to blend even better than on short-grass prairie. The head of the owl and the lobe of the cactus presented similar silhouettes, and against the sun it took hard looking to spot the owls.

To find only two families on close cropped, tame grass pasture was puzzling. Of course breaking the prairie sod to sow tame grasses would likely destroy any existing burrows and mounds, and interrupt the tradition of repetitive occupancy where owls had been present. However, ground squirrels and badgers have repopulated some of these fields. There is the appearance of suitable owl habitat. Exchanging tame grass for native cover would not seem to be a deterrent where a stock of burrows and mounds exists, yet for some reason it is. A large part of the Region, 320,000 acres is devoted to community pastures. Our assumption was that owls should be found in such pastures in the south half of the Sector. Cruising 51 miles of trails alongside and through them changed our minds. Lots of Swainson's Hawks, many Chestnut-collared Longspurs, several antelope, a few ground squirrels, but not a single owl. There is one report of an owl family in the Dundrun pasture in 1968.

Some community pastures, such as Grainland, south of Elbow, are largely on sandy soils and the resulting small number of burrows may account for the lack of owls. Other community pastures are on medium soils, such as Willner and the Co-op west of Davidson and Aylesbury, but the ground squirrel populations in them are generally small. This may result from lighter grazing here than in private range pastures. Further, much of the acreage is in tame grasses. In sum, most of the area in community pastures simply does not fit the model for Burrowing Owl habitat. Yet parts of the Willner and Dundurn pastures are typical habitat with stocks of burrows, but for some reason are not occupied by owls. 
Amount of Habitat, Unfilled Niches. In many districts farmyard pastures are almost a thing of the past: in seven miles between Sovereign and Zealandia, none; in 18 miles, Dinsmore to Macrorie, four; in 20 miles, Elbow to Hawarden, four or five; in 18 miles south from Kenaston, five; in nine miles, Brownlee north to the Qu'Appelle Valley, two. Also, not all farmyard pastures meet owl requirements. Similarly, range pastures are rare or non-existent in many districts and suitable habitat occurs in only a minority of these fields. Thus the total amount of habitat is very small but small as the amount may be, only a fraction of the number of the fields considered fit for owls were actually occupied. By comparison, whereas one expects to see Mallards on most "good" prairie sloughs, to find Burrowing Owls in a "good" prairie pasture was the exception. Regrettably no record was kept on the frequency of occupancy but the impression was that owls were found in only one of every 15 or so suitable fields. Moreover, judging from the density of occupancy in the one major colony, a number of occupied fields had sufficient burrows for additional families.

Of the 45 families located in 1975 , 10 were in farmyard pastures and 30 were in range pastures. Three of the former and 15 of the latter, less than half the total number, were on tracts thought to be akin to natural habitat, that is, the land was marginal and the grasses would probably have been sufficiently stunted even without grazing.

Conversely, seven of the families in farmyard pastures and 15 of those in range pastures, or $55 \%$ of such families, were on better soil, land rendered suitable for owls only by moderate to intensive grazing (or, in one or two instances, possibly by intensive cropping by ground squirrels). As this situation is due to man's stock management practices, owl habitat on good soils should really be looked upon as artificial. A change to less intensive grazing would likely result in these tracts having grass too verdant for the owl's liking - as was observed in abandoned pastures.

A continuation of trends in agricultural practices and in rural life style could result in some owloccupied farmyard pastures passing out of existence. Advances in the technology for handling poor soils could lead to some range pastures being connected to tame grasses or planted to crops.

Exceptional Sites. Ten sites recorded since 1952 were so different from typical habitat as to warrant mention. A family occupied a burrow in a plowed field in 1969; R. E. Gehlert banded the young. Two sites were in urban areas. A pair was seen at burrows on the Saskatoon Airport in July, 1968, although it is not known if they raised young. A bird occupied a burrow on the university campus in Saskatoon in the spring of 1972 but remained only two weeks. Within a hundred yards or so of this burrow were two shelterbelts, a secondary highway, an arterial road, a parking lot, farm structures and other buildings. In 1962, J. B. Gollop found a family using a road culvert as a nest burrow.

Prior to 1975 owls had been observed at four places along the right-ofway of the Canadian National Railway's Saskatoon-Rosetown line. One occupancy was at least three years, another at least two. Thus I thought that railway right-of-way might form a major habitat type. Of 205 miles of track in the region paralleled by roads, 183 miles were checked for owls. Portions were scanned - for males using fence posts or poles as sentinel perches - more than once in connection with other trips. Only two new sites resulted, both along the Saskatoon-Rosetown line, and just one former site was in use in 1975. Two of the active burrows and two of the earlier ones were in badgerlike holes. All three active sites had a number of secondary holes.

Apparently the bird's primary drive is to seek out a burrow and any motivation for "flat, treeless, short- 
grass country" was submerged in all instances of atypical habitat.

The Past. Though the Burrowing Owl was more numerous here in the recent past, was it always more numerous or ever really common? As much of today's population is associated with artificial habitat (intensive grazing), history could be significant when attempting to assess the future. The experience of six informed men who travelled in central Saskatchewan in earlier times are particularly relevant.

Thomas Blakiston, in April-May of 1858 while on a buffalo hunt from Fort Carlton to the Anerley Lakes country in the heart of the Region, collected bird specimens and eggs. In 1859 the Earl of Southesk spent most of July in the Region from the Eyebrow Hills to Eagle Creek. He commented on a number of plants, birds and animals including badgers and ground squirrels. In the 1930's, O. C. Furniss, a Prince Albert naturalist, while bicycling from Biggar to Swift Current, kept track of the gradual decrease in abundance of northern plains birds and the corresponding increase of the more southerly species. Blakiston and Southesk, in particular, had superior observation platforms, the backs of horses. Not one of these three observers mentioned the Burrowing Owl. Since they kept diaries, for all to overlook noting the species seems beyond reasonable coincidence, especially a diurnal owl with such distinctive appearance, curious alarm display, unique nesting habit and complete lack of secretiveness in spring and summer. They probably never saw a Burrowing Owl. The two earlier records are of particular interest since they were made before the disappearance of the buffalo and prior to human settlement.

H. H. Mitchell, the provincial government naturalist, wrote in 1924 that the owl was "not noted breeding north of Davidson." According to Todd a Carnegie Museum specimen collecting party, headquartered in Davidson and working the country from Elbow to Quill Lakes in May and June, 1932, met with Burrowing Owls

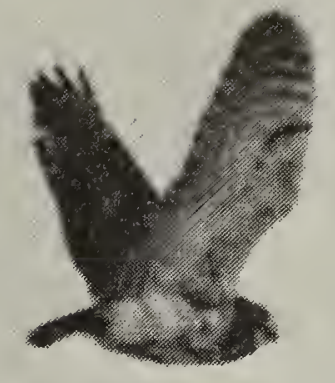

Burrowing Owl flying. Gary Anweiler

only twice. J. Dewey Soper, who made numerous bird surveys for the federal government and who was in the Region in seven of the years between 1939 and 1949, saw the bird just once, near Elrose in 1942.

Reports from southeast of the Region, imply that the owl moved in there after human settlement. Grant noted that the first record in Minnesota was in 1881, and that it increased up to 1924. According to T. E. Seton, Manitoba's first report was in 1897 and around 1900 the bird was rare but increasing. Cartwright wrote that by 1931 it was not uncommon. John Macoun, travelling westward along the International Boundary in 1879-80, did not see the bird until he reached the Frenchman River, south of our Region. Yet Mitchell, writing mainly of the second decade of this century, reported the owl not uncommon in Saskatchewan but more numerous in the extreme southeast of the province. Presumably referring to the 1920's or earlier, Taverner gave the CPR mainline as about the northern limit in the Prairie Provinces but Macoun reported it north of Moose Jaw as early as 1896. Although Brenckle found enough owls in South Dakota in 1931 and 1934 to band 376. Grant in 1963-64 crossed the Dakotas six times specifically looking for these birds and could find only 13 pairs. 
To the south and southwest of the Region, Macoun, who noted the bird in both prairie dog and ground squirrel colonies in 1879-80, reported it at Rush Lake in 1891. There are other scattered observations from that period. A. C. Bent located only three pairs in 1905-06. These records indicate that the owl has always been present, but rare, in the arid southwest. Reports from the 1920's and 1930's suggest a small, scattered population to the south of our Region. Soper writing in the Canadian FieldNaturalist summed up the 1927-41 post-settlement situation as follows: "Sometimes long distances can be covered in southern Alberta and Saskatchewan without observing any, though this is typical Burrowing Owl territory."

Likely the Burrowing Owl has always been present here at the northern extremity of the Province's southwestern population. Prior to human settlement the bird was extremely rare, being confined to a few, scattered, sparsely vegetated tracts, places not attractive to travellers. Settlement, which occurred mainly in the period 1895 to 1920 , led to intensive pasturing, a condition not present when buffalo, and later cattle, ranged freely. Countless environments attractive to gophers, and thus owls, resulted. It is quite possible there was virtually an owl population explosion, peaking in the 1920's and 1930's. But numbers never rose to the point where the bird was generally common, except perhaps in some districts, or anywhere near filled available habitat. Already at play were factors prejudicial to the bird's welfare, first limiting population growth and then leading to a long, still continuing decline.

In Perspective. Burrowing Owl habitat in this region is very scarce, with the possibility of it becoming more so, and most of what exists is artificial, the result of man's activities. Truly natural habitat occurs only in parts of the extreme southwest corner of the region and in scattered soil discontinuities elsewhere. Though the stock of habitat is small, it is a long way from being filled, and can hold a much larger number of the birds.

The population of ground owls is small, perhaps 100 to 200 breeding pairs in the entire Region, or roughly one pair per 70 square miles. The general view is that numbers were greater at one time. Yet I suggest that the present Regional population is higher than it was before human settlement, even though the continental population was apparently greater then. Why the population here is currently low and evidently still decreasing is not known. Next to nothing is known about hazards faced by the owl, although road kill could be a major one.

As an adult bird spends almost half its annual cycle in the Region, factors influencing its welfare here are important. However, as the bird apparently has an inherent need for ready access to burrows the year round, the availability of these on the winter range, and perhaps during migration, could also be significant. Little is known about this aspect of the local population's life cycle.

In my opinion the owl is an unadaptable, highly specialized bird in a very narrow niche, dependent for its nest on animals which are subject to control programs, and dependent for its food largely on the grasshopper which is the object of poison programs. Our population has not adapted to tame grass pastures replete with burrows and grasshoppers, nor to sandy pastures as it has in Nebraska, nor to grain and stubble fields as it has in California.

The Burrowing Owl in central Saskatchewan is in a bad way and we aren't sure of the causes. In the United States owl population declines are often associated with loss of habitat, but, as far as the recent decrease here is concerned, we really can't say that is the case. Until we do know the reason, we are not in much of a position to take meaningful remedial action, if such is possible and desired. We need more definitive studies in order to get answers - a furrowing brow for the Burrowing Owl. 
ACTON, J. G. et al 1968. The Soils of the Rosetoun Map Area. University of Saskatchewan

BAILEY, F. M. 1928. Birds of New Mexico. New Mexico Dept. Game and Fish, Santa Fe. 807 p.

BENT, A. C. 1908. Summer birds of southwestern Saskatchewan. Auk. 25:25-35.

BLAKISTON, THOMAS, 1858. Personal letter, Saskatchewan Archives, Saskatoon.

BRENCKLE, J. F. 1936. The migration of the Western Burrowing Owl. Bird-Banding 7:166168.

BUTTS, K. O. 1971. Observations on the ecology of Burrowing Owls in western Oklahoma, a preliminary report. Proc. Okla. Acad. Sci. 51:6674.

CARTWRIGHT, B. W. 1931. Notes and observations on some Manitoban birds. Can. FieldNat. 45:181-187

COULOMBE, H. N. 1971. Behavior and population ecology of the Burrowing Ow', Speotyto cunicularia, in the Imperial Valley of California. Condor 73:162-176.

ECKERT, A. W. 1974. The owls of North America. Doubleday, Garden City. 278 p.

FURNISS, O. C. Diaries (unpublished).

GODFREY, W. E. 1966. The birds of Canada. Queen's Printer, Ottawa. 428 p.

GRANT, R. A. 1965. The Burrowing Owl in Minnesota. Loon 37:2-17.

GRINNEL, JOSEPH, and MILLER, A. H. 1944. The distribution of the hirds of California. Cooper Ornithological Club, Pacific Cost Avifauna 27. $608 \mathrm{p}$.

GRINNEL, J., and SWARTH, H. S. 1913. An account of the birds and mammals of the San Jacinto area of southern California. University of California Publications 10:197-406.

LIGON, J. S. 1961. New Mexico birds. Univ. of New Mexico Press. Albuquerque. 360 p.

MACOUN, JOHN, and J. M. MACOUN. 1909 Catalogue of Canadian birds. Government Printing Bureau, Ottawa. 761 p.

MARTIN, D. J. 1973. Selected aspects of Burrowing Owl ecology and behavior. Condor 75:446-456.

MITCHELL, H. H. 1924. Birds of Saskatchewan. Can. Field-Nat. 38:101-118.

POUGH, R. H. 1953. Audubon Guides. All the birds of eastern and central North America. Doubleday, Garden City. $312+352$ p.

RICHARDS, J. H., and K. I. FUNG. 1969. Atlas of Saskatchewan. Univ. of Saskatchewan, Saskatoon. 236 p.

ROY, J. F. 1964. Birds of the Elbow. Saskatchewan Natural History Society, Regina. 33 p.

SASKATOON BIRD SURVEY file. Observers whose records have been used are: $R$. E. Gehlert, J. B. Gollop, J. Greaves, G. A. Hardy, W. C. Harris, C. S. Houston, W. S. Richards, S. J. Shadick, J. A. Wedgwood, D. W. Whitfield (unpublished).

SETON, E. T. 1908. Recent bird records for Manitoba. Auk. 25:450-454.
SOPER, J, D. 1949. Notes on the fauna of the former Nemiskam National Park and vicinity. Alherta. Can. Field-Nat. 63:167-182.

SOPER, J. D. 1970. Unpublished field notes on the birds observed and collected in the province of Saskatchewan, Canada, in 1917, 1921, 1927 and from July, 1937 to September, 1947. Univ. of Alberta, Edmonton. 119 p.

SOUTHESK, EARL OF, 1969. Saskatchewan and the Rocky Mountains. M. G. Hurtig Ltd., Edmonton (reprint).

TAVERNER, P. A. 1934. Birds of Canada. King's Printer, Ottawa. 445 p.

THOMSEN, LISE. 1971. Behavior and ecology of Burrowing Owls on the Oakland Municipal Airport. Condor 73:177-192.

TODD, W. E. C. 1947. Notes on the hirds of southern Saskatchewan. Annals Carnegie Mus. 30:383-421.

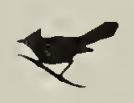

\section{BURROWING OWL INFORMATION WANTED}

In 1972, the Canadian Wildlife Service embarked on a program to locate Burrowing Owl sites on the prairies. W. E. Renaud did some initial work, began the compilation of a list of then known sites and solicited information on others. The project could not be completed at that time.

Anyone knowing the location of a nest burrow not previously reported is asked to inform the Canadian Wildlife Service, 115 Perimeter Road, Saskatoon, Sask. S7N 0X4. Information should include description of the location (sectiontownship-range or distance and direction from the nearest town or other readily identifiable feature), and give details of the site (type of field, kind of ground cover). Please also give years or period the site was known to have been active. Although complete, accurate descriptions of currently active sites are the most valuable, any leads about the locations of breeding birds will be welcomed. 